\title{
Studi Deskriftif Pelaksanaan Sasaran Keselamatan Pasien Sesuai Instruksi Kars Versi 2012 di IGD Rumah Sakit TNI AD Tk IV 02.07.04 Bandar Lampung
}

\author{
Arseliana Helsanewa ${ }^{1}$, Achmad Rifai ${ }^{2}$, Jamaluddin ${ }^{3}$ \\ ${ }^{1,2,3}$ Magister Kesehatan Masyarakat Insitut Kesehatan Helvetia \\ Jl. Pangeran Raya Desa Kenten Laut Kec. Talang Kelapa 30716, Telp: +6285207332532 \\ Email : ${ }^{1}$ helsanewa@gmail.com, ${ }^{2}$ achmad.fifai@gmail.com, ${ }^{3}$ drjamal_bror@yahoo.com
}

\begin{abstract}
Abstrak
Rumah sakit TNI AD Tk IV Bandar Lampung ini merupakan salah satu rumah sakit yang berkomitmen pada keselamatan pasien dan telah memiliki SPO (Standar Prosedur Operasional). Penelitian ini bertujuan untuk menggambarkan sejauh mana pelaksanaan standar sasaran keselamatan pasien yang sesuai dengan Instruksi KARS versi 2012 di Instalasi Gawat Darurat RS TNI AD Tk. IV 02.07.04 Bandar Lampung tahun 2017. Penelitian ini menggunakan metode kualitatif. Jumlah Informan dalam penelitian ini adalah 7 tenaga kesehatan pelaksana antara lain Dokter, Tenaga keperawatan dan Petugas apoteker di Instalasi Gawat Darurat RS TNI AD Tk IV Bandar Lampung. Hasil penelitian menunjukkan bahwa pelaksanaan identifikasi pasien, pelaksanaan komunikasi efektif, pelaksanaan peningkatan keamanan obat yang perlu diwaspadai, pelaksanaan kepastian tepat-lokasi, tepat-prosedur, tepat-pasien operasi, dan pelaksanaan pengurangan risiko infeksi terkait pelayanan kesehatan sudah sesuai dengan instrumen KARS versi 2012, sedangan pelaksanaan risiko pasien jatuh belum sesuai dengan instrumen KARS versi 2012. Pelaksanaan Standar standar sasaran I,II,III, IV, dan V keselamatan pasien sesuai dengan Instalasi KARS versi 2012 di Instalasi Gawat Darurat RS TNI AD Tk. IV 02.07.04 Bandar Lampung tahun 20I7, sedangkan sasaran VI belum sesuai dengan Instruksi KARS versi 2012. Disarankan memperhatikan ketersediaan sarana dan prasarana di Instalasi Gawat Darurat guna mendukung pelaksanaan sasaran keselamatan pasien.
\end{abstract}

Kata kunci : Rumah sakit, Sasaran keselamatan pasien, Akreditasi

\section{Abstract}

This hospital is one of the hospitals committed to patient safety and has SPO (Standard Operating Procedure). This study aims to descriptive the extent to which the implementation of target patient safety standards in accordance with KARS Instruction 2012 version in Emergency Installation RS TNI AD Tk. IV 02.07.04 Bandar Lampung i 20I7. This study uses a qualitative method. The number of informants in this research are 7 implementing health personnel such as Doctor, Nursing Staff and Pharmacist Officer at Emergency Installation RS TNI AD Tk IV Bandar Lampung. The results of the study indicate that the implementation of patient identification, effective communication execution, safety enhancement implementation that need to be watched, precise location-correct, precise-procedure, exact-operation operation, and implementation of risk reduction related to health services are in accordance with KARS instrument 2012 , while the implementation of the risk of falling patients is not in accordance with KARS instrument 2012 version. Implementation Standards standard I, II, III, IV, and $V$ target standards of patient safety in accordance with KARS Installation 2012 version at Emergency Installation RS TNI AD Tk. IV 02.07.04 Bandar Lampung in 20I7, while the target VI is not in accordance with KARS Instruction 20I2. 20I2. It is suggested to pay attention to the availability of facilities and infrastructure in the Emergency Installation to support the implementation of the patient's safety goals.

Keywords : Hospitals, Patient safety goals, Accreditation 


\section{Pendahuluan}

Rumah sakit merupakan tempat yang sangat kompleks yang terdapat berbagai macam obat, tes dan prosedur, banyak alat dengan teknologinya, berbagai jenis tenaga profesi dan non profesi yang siap memberikan pelayanan pasien 24 jam terus menerus. Keberagaman dan kerutinan pelayanan tersebut apabila tidak dikelola dengan baik dapat menimbulkan peluang untuk terjadinya kesalahan pelayanan yang dapat berakibat terhadap keselamatan pasien. Pasien sebagai pengguna pelayanan kesehatan berhak memperoleh keamanan dan keselamatan dirinya selama dalam perawatan di rumah sakit. ${ }^{1}$

Organisasi kesehatan dunia (WHO) telah menegaskan pentingnya keselamatan dalam pelayanan kepada pasien. Publikasi WHO pada tahun 2004, mengumpulkan angka-angka penelitian rumah sakit di berbagai negara Amerika, Inggris, Denmark, dan Australia, ditemukan KTD dengan rentang 3,2-16,6\%. Dengan datadata tersebut, berbagai negara segera melakukan penelitian dan mengembangkan Sistem Keselamatan Pasien. ${ }^{2}$

Saat ini isu penting dan global dalam pelayanan kesehatan adalah keselamatan pasien (patient safety). Isu ini praktis mulai dibicarakan kembali pada tahun 2000an, sejak laporan dari Institute of Medicine (IOM) yang menerbitkan laporan To Err Is Human, Building A Safer Health System dan memuat data menarik tentang Kejadian Tidak Diharapkan/KTD (Adverse Event). Laporan itu mengemukakan penelitian di rumah sakit di Utah dan Colorado serta New York. Di Utah dan Colorado ditemukan KTD (adverse event) sebesar $2,9 \%$, dimana $6,6 \%$ di antaranya meninggal. Di New York KTD adalah sebesar 3,7\% dengan angka kematian 13,6\%. Angka kematian akibat KTD pada pasien rawat inap di seluruh Amerika yang berjumlah 33,6 juta per tahun berkisar $44.000-98.000$ per tahun. ${ }^{3}$

Di Indonesia data tentang Kejadian Tidak Diharapakan (KTD) dan Kejadian Nyaris Cedera (KNC) masih sulit didapatkan. Laporan insiden keselamatan pasien berdasarkan provinsi pada tahun 2007, ditemukan provinsi DKI Jakarta menempati urutan tertinggi yaitu $37,9 \%$ di antara delapan provinsi lainnya, yaitu Jawa Tengah 15,9 \%, D.I. Yogyakarta 18,8\%, Jawa Timur $11,7 \%$, Sumatera Selatan $6,9 \%$, Jawa Barat 2,8\%, Bali 1,4\%, Aceh $10,7 \%$ dan Sulawesi Selatan 0,7\%. (3) Menurut Utarini, keselamatan pasien telah menjadi perhatian serius. Dari penelitiannya terhadap pasien rawat inap di 15 rumah sakit dengan 4500 rekam medik menunjukkan angka KTD yang sangat bervariasi, yaitu $8,0 \%$ hingga $98,2 \%$ untuk diagnostic error dan 4,1\% hingga $91,6 \%$ untuk medication error. ${ }^{4}$

Sejak berlakunya UU No. 8 Tahun 1999 tentang Perlindungan Konsumen dan UU No. 29 tentang Praktik Kedokteran, muncul berbagai tuntutan hukum kepada dokter dan rumah sakit. Hal ini hanya dapat ditangkal apabila rumah sakit menerapkan sistem keselamatan pasien. Perhimpunan Rumah Sakit Seluruh Indonesia (PERSI) telah membentuk Komite Keselamatan Pasien Rumah Sakit (KKP-RS) pada tanggal 1 Juni 2005. Selanjutnya Gerakan Keselamatan Pasien Rumah Sakit ini kemudian dicanangkan oleh Menteri Kesehatan pada Seminar Nasional PERSI pada tanggal 21 Agustus 2005, di Jakarta. ${ }^{2}$

Instalasi Gawat Darurat merupakan unit pelayanan yang sangat rentan dengan keselamatan pasien. Karena Instalasi Gawat Darurat rumah sakit mempunyai tugas menyelenggarakan pelayanan asuhan medis dan asuhan keperawatan sementara serta pelayanan pembedahan darurat, bagi pasien yang datang dengan gawat darurat medis. Pelayanan pasien gawat darurat adalah pelayanan yang memerlukan pelayanan segera, yaitu cepat, tepat dan cermat untuk mencegah kematian dan kecacatan. ${ }^{5}$

Undang-Undang No 012 Tahun 2012 tentang Akreditasi Rumah Sakit, disebutkan bahwa akreditasi bertujuan meningkatkan keselamatan pasien rumah 
sakit dan meningkatkan perlindungan bagi pasien, masyarakat, sumber daya manusia rumah sakit dan rumah sakit sebagai institusi. Sejak tahun 2012, akreditasi rumah sakit mulai beralih dan berorientasi pada paradigma baru dimana penilaian akreditasi didasarkan pada pelayanan berfokus pada pasien. Keselamatan pasien menjadi indikator standar utama penilaian akreditasi baru yang dikenal dengan akreditasi rumah sakit versi 2012 ini. Dalam standar akreditasi rumah sakit versi 2012, mencakup standar pelayanan berfokus pada pasien, standar manajemen rumah sakit, sasaran keselamatan pasien di rumah sakit dan standar program MDGs. ${ }^{6}$

Rumah sakit TNI AD Tk IV Bandar Lampung ini merupakan salah satu rumah sakit yang berkomitmen pada keselamatan pasien dan telah memiliki SPO (Standar Prosedur Operasional) penerapan keselamatan pasien sejak bulan November tahun 2013. ${ }^{7}$ Tercatat kejadian pasien jatuh, 2 pasien terjadi di IGD pada bulan Maret-April 2013, dan setelah dilakukan penerapan patient safety pada tahun 2014 sampai bulan September terdapat 1 pasien jatuh. ${ }^{8}$ Berdasarkan hal di atas peneliti tertarik untuk menggambarkan pelaksanaan sasaran keselamatan pasien sesuai dengan Instruksi Akreditasi Rumah Sakit versi 2012 di Instalasi Gawat Darurat RS TNI AD Tk. IV 02.07.04 Bandar Lampung tahun 2017.

\section{Metode Penelitian}

Penelitian ini menggunakan metode kualitatif yang bertujuan untuk menggambarkan pelaksanaan sasaran keselamatan pasien dengan menggunakan wawancara mendalam (indepth interview) dan observasi terus terang atau tersamar untuk mendapatkan informasi. Populasi subjek (Informan) dalam penelitian ini adalah unsur yang sedang terlibat dan atau memiliki pengetahuan berkaitan dengan kebijakan Permenkes NO 11 Tahun 2017 tentang Keselamatan Pasien Rumah Sakit TNI AD Tk IV Bandar Lampung. ${ }^{9}$ Jumlah Informan dalam penelitian ini adalah 7 tenaga kesehatan pelaksana antara lain Kepala Ruangan Gawat Darurat (1), Dokter (2), Tenaga keperawatan (3) dan Petugas Apoteker (1) di Instalasi Gawat Darurat RS TNI AD Tk IV 02.07.04 Bandar Lampung. Penelitian ini dilakukan di Instalasi Gawat Darurat RS TNI AD Tk IV Bandar Lampung. Waktu penelitian ini dilakukan adalah Februari sampai September 2017.

Prosedur analisa data dalam penelitian ini dilakukan dengan cara membaca transkrip secara berulang-ulang dan teliti untuk mendapatkan pemahaman tentang pengalaman yang dialami informan dalam Pelaksanaan standar sasaran keselamatan pasien di IGD. Selanjutnya peneliti mengidentifikasi kata kunci yang terdapat pada setiap kalimat dan memberikan tanda garis bawah. Selanjutnya peneliti mengambil arti dari kata kunci yang merupakan pernyataan informan untuk menentukan kategori. Selanjutnya kategori-kategori dikelompokkan dalam tema.Untuk menjamin keabsahan informasi dalam penelitian ini, peneliti mengadakan triangulasi sumber pegumpulan data dan triangulasi metode.

\section{Hasil Penelitian}

Informan dalam penelitian inis ejumlah 7 responden yang terdiri dari $\mathrm{Ka}$. Ruangan IGD RS TNI AD Tk. IV 02.07.04 Bandar Lampung, dokter IGD RS TNI AD Tk. IV 02.07.04 Bandar Lampung, perawat IGD RS TNI AD Tk. IV 02.07.04 Bandar Lampung, dan Petugas Apoteker IGD RS TNI AD Tk. IV 02.07.04 Bandar Lampung.

Dari tabel 2 dapat dilihat dari 3 dokter dan 3 perawat yang dilakukan observasi, semuanya sudah melakukan identifikasi pasien sesuai dengan standar. Pada table di atas dapat dilihat bahwa hasil yang didapat adalah TP (Tidak Pernah) karena perawat dan dokter selama penelitian tidak pernah memberikan ataupun menerima perintah melalui 
Tabel 1. Karakteristik Informan

\begin{tabular}{lllc}
\hline \multicolumn{2}{c}{ Informan } & \multicolumn{1}{c}{ Jabatan/Asal } & Jml \\
\hline Informan 1 (P1) & Kepala Ruangan IGD & Dokter/IGD RS TNI AD Tk. IV 02.07.04 Bandar & 1 orang \\
& & Lampung & 1 orang \\
Informan 2 (P2) & Dokter IGD & IGD RS TNI AD Tk. IV 02.07.04 Bandar Lampung & 1 orang \\
Informan 3 (P3) & Dokter IGD & IGD RS TNI AD Tk. IV 02.07.04 Bandar Lampung & 1 orang \\
Informan 4 (P4) & Perawat & IGD RS TNI AD Tk. IV 02.07.04 Bandar Lampung & 1 orang \\
Informan 5 (P5) & Perawat & IGD Rumkit TNI AD Tk. IV 02.07.04 Bandar & \\
& & Lampung & 1 orang \\
Informan 6 (P6) & Perawat & IGD RS TNI AD Tk. IV 02.07.04 Bandar Lampung & orang \\
Informan 7 (A1) & Apoteker & IGD RS TNI AD Tk. IV 02.07.04 Bandar Lampung & . \\
\hline
\end{tabular}

Tabel 2. Pelaksanaan Sasaran Keselamatan Pasien IGD

\begin{tabular}{|c|c|c|c|c|c|c|}
\hline Sasaran & D1 & D2 & D3 & P1 & $\mathbf{P 2}$ & $\mathbf{P 3}$ \\
\hline \multicolumn{7}{|l|}{ Sasaran I Keselamatan Pasien (Identifikasi Pasien) } \\
\hline Pasien diidentifikasi menggunakan dua identitas pasien & $\mathrm{Y}$ & $\mathrm{Y}$ & $\mathrm{Y}$ & $\mathrm{Y}$ & $\mathrm{Y}$ & $\mathrm{Y}$ \\
\hline $\begin{array}{l}\text { Pasien diidentifikasi sebelum pemberian obat, darah atau produk } \\
\text { darah }\end{array}$ & $\mathrm{Y}$ & $\mathrm{Y}$ & Y & $\mathrm{Y}$ & $\mathrm{Y}$ & $\mathrm{Y}$ \\
\hline $\begin{array}{l}\text { Pasien diidentifikasi sebelum mengambil darah dan specimen lain } \\
\text { untuk pemeriksaan klinis }\end{array}$ & $\mathrm{Y}$ & Y & Y & $\mathrm{Y}$ & Y & $\mathrm{Y}$ \\
\hline Pasien diidentifikasi sebelum pemberian pengobatan atau tindakan & $\mathrm{Y}$ & $\mathrm{Y}$ & $\mathrm{Y}$ & $\mathrm{Y}$ & $\mathrm{Y}$ & $\mathrm{Y}$ \\
\hline \multicolumn{7}{|l|}{ Sasaran II Keselamatan Pasien (Komunikasi efektif) } \\
\hline $\begin{array}{l}\text { Perintah lisan melalui telepon atau hasil pemeriksaan dituliskan } \\
\text { secara lengkap oleh penerima perintah atau hasil pemeriksaan } \\
\text { tersebut }\end{array}$ & $\mathrm{TP}$ & TP & $\mathrm{TP}$ & ТP & TP & TP \\
\hline $\begin{array}{l}\text { Perintah lisan dan melalui telepon dibacakan kembali oleh penerima } \\
\text { perintah }\end{array}$ & $\mathrm{TP}$ & $\mathrm{TP}$ & $\mathrm{TP}$ & ТP & $\mathrm{TP}$ & $\mathrm{TP}$ \\
\hline $\begin{array}{l}\text { Perintah atau hasil pemeriksaan dikonfirmasi oleh individu yang } \\
\text { memberi perintah }\end{array}$ & $\mathrm{TP}$ & TP & $\mathrm{TP}$ & $\mathrm{TP}$ & $\mathrm{TP}$ & $\mathrm{TP}$ \\
\hline \multicolumn{7}{|c|}{$\begin{array}{l}\text { Pelaksanaan Sasaran IV Keselamatan Pasien (Kepastian tepat lokasi, tepat prosedur, dan tepat pasien } \\
\text { operasi) }\end{array}$} \\
\hline $\begin{array}{l}\text { Memberikan tanda yang jelas dan dapat dimengerti untuk } \\
\text { identifikasi operasi }\end{array}$ & $\mathrm{Y}$ & $\mathrm{Y}$ & $\mathrm{Y}$ & $\mathrm{Y}$ & $\mathrm{Y}$ & $\mathrm{Y}$ \\
\hline $\begin{array}{l}\text { Melibatkan pasien saat checklist atau penandaan sebelum melakukan } \\
\text { tindakan hecting }\end{array}$ & $\mathrm{Y}$ & Y & Y & $\mathrm{Y}$ & Y & $\mathrm{Y}$ \\
\hline \multicolumn{7}{|l|}{ Pelaksanaan Sasaran V Keselamatan Pasien (Pengurangan risiko infeksi) } \\
\hline Mencuci tangan sebelum melakukan tindakan & $\mathrm{Y}$ & Y & Y & $\mathrm{Y}$ & Y & $\mathrm{Y}$ \\
\hline Mencuci tangan sebelum menyentuh pasien & $\mathrm{Y}$ & $\mathrm{Y}$ & $\mathrm{Y}$ & $\mathrm{Y}$ & $\mathrm{Y}$ & $\mathrm{Y}$ \\
\hline Mencuci tangan setelah terkena cairan tubuh pasien & $\mathrm{Y}$ & Y & Y & $\mathrm{Y}$ & Y & $\mathrm{Y}$ \\
\hline Mencuci tangan setelah melakukan tindakan & $\mathrm{Y}$ & Y & $\mathrm{Y}$ & $\mathrm{Y}$ & $\mathrm{Y}$ & $\mathrm{Y}$ \\
\hline Mencuci tangan setelah memegang daerah sekiling pasien & $\mathrm{Y}$ & Y & Y & $\mathrm{Y}$ & Y & $\mathrm{Y}$ \\
\hline Mencuci tangan dengan langkah cuci tangan dari WHO & $\mathrm{Y}$ & $\mathrm{Y}$ & $\mathrm{Y}$ & $\mathrm{Y}$ & $\mathrm{Y}$ & $\mathrm{Y}$ \\
\hline \multicolumn{7}{|c|}{ Pelaksanaan Sasaran VI Keselamatan Pasien (Pengurangan risiko pasien jatuh) } \\
\hline Melakukan asesmen awal risiko pasien jatuh & $\mathrm{Y}$ & $\mathrm{Y}$ & $\mathrm{Y}$ & $\mathrm{Y}$ & $\mathrm{Y}$ & $\mathrm{Y}$ \\
\hline $\begin{array}{l}\text { Melakukan asesmen ulang terhadap pasien bila diindikasikan terjadi } \\
\text { perubahan kondisi atau pengobatan }\end{array}$ & $\mathrm{Y}$ & Y & Y & $\mathrm{Y}$ & $\mathrm{Y}$ & $\mathrm{Y}$ \\
\hline
\end{tabular}

Ket: $\mathrm{Y}=\mathrm{Ya}$; $\mathrm{D}=$ Dokter; $\mathrm{T}=$ Tidak; $\mathrm{P}=$ Perawat; $\mathrm{TP}=$ Tidak Pernah

telepon, karena dokter selalu stand by selama jaga, sehingga dapat dikatakan bahwa komunikasi dokter dan perawat di Unit Gawat Darurat sudah efektif. Dari tabel di atas dapat dilihat bahwa sasaran IV sudah terlaksana dengan baik, dari 3 dokter dan 3 perawat yang diamati semuanya telah melakukan tepat lokasi, tepat 
prosedur dan tepat pasien operasi sesuai dengan standar. Dari hasil observasi pelaksanaan pencegahan infeksi dari cuci tangan dengan handrub, dapat dilihat dari tabel di atas bahwa dokter dan perawat sudah melakukan 5 momen cuci tangan sesuai dengan pedoman 5 momen cuci tangan. Sehingga dapat dikatakan bahwa mencuci tangan sesuai dengan 6 langkahlangkah dalam 5 momen cuci tangan dengan handrub atau dengan handwash sudah efektif dilakukan baik oleh dokter dan perawat di IGD. Dari tabel di atas dapat dilihat bahwa perawat dan dokter yang diobservasi telah melakukan asesmen pasien dengan resiko jatuh sesuai dengan standar.

Dari tabel 3 dapat dilihat bahwa tersedia gelang identitas untuk pasien, tetapi belum lengkap karena tidak ada penanda gelang warna ungu karena masih dalam proses pemesanan.
Dari tabel 3 dapat dilihat bahwa lemari khusus untuk penyimpanan obat high alert dan elekrolit konsentrat sudah ada, label khusus obat high alert dan elektrolit konsentrat juga sudah ada. Dari tabel di atas dapat dilihat bahwa wastafel dan air ada. Pengering tangan berupa tissu atau hand dryer ada tapi tissu sering kosong. Handrub dan sabun selalu ada.

Dari tabel di atas dapat dilihat bahwa tersedia bed side rail tetapi tidak di semua tempat tidur pasien tersedia, pegangan besi (hand rail) tidak dipasang di toilet, lantai bukan antislip dan kursi roda selalu ada.

Hasil penelitian dpat dilihat bahwa penempatan obat-obat high alert dan elektrolit konsentrat disimpan di tempat terpisah dan tidak berada di unit pelayanan pasien, melainkan di apotek untuk kasus tidak darurat.

Tabel 3. Observasi Sarana dan Prasarana dalam Pelaksanaan Sasaran Keselamatan Pasien IGD

\begin{tabular}{lcc}
\hline \multicolumn{1}{c}{ Sarana/ prasarana } & Ketersediaan & Keterangan \\
\hline Gelang identitas & Y & Tidak lengkap \\
Keamanan Obat & & - \\
Lemari khusus obat high-alert & Y & - \\
Lemari khusus elekrolit konsentrat & Y & - \\
Label khusus & Y & \\
Pengurangan risiko infeksi & & - \\
Wastafel & Y & \\
Air & Y & Selalu ada \\
Sabun & Y & Sering kosong \\
Pengering tangan & Y & Selalu ada \\
Handrub & Y & \\
Pengurangan risiko pasien jatuh & & Tidak semua bed \\
Bed side rail & Y & - \\
Kursi roda & Y & - \\
Pegangan besi di toilet & T & - \\
Lantai antislip & T & \\
\hline
\end{tabular}

Ket: $\mathrm{Y}=\mathrm{Ya}$; $\mathrm{T}=$ Tidak

Tabel 4. Pelaksanaan Sasaran III Keselamatan Pasien (Keamanan Obat) IGD

\begin{tabular}{lcc}
\hline \multicolumn{1}{c}{ Sasaran III } & A1 \\
\hline Menyimpan obat-obat high-alert di tempat terpisah & Y \\
Menyimpan elektrolit konsentrat di tempat terpisah & Y \\
$\begin{array}{l}\text { Elektrolit konsentrat tidak berada di unit pelayanan pasien kecuali jika } \\
\text { dibutuhkan dan bila diperkenankan kebijakan }\end{array}$ & Y \\
$\begin{array}{l}\text { Elektrolit konsentrat yang disimpan di unit pelayanan pasien diberi label yang } \\
\text { jelas dan disimpan pada area yang dibatasi ketat (restricted) }\end{array}$ & Y \\
\hline
\end{tabular}

Ket: $\mathrm{Y}=\mathrm{Ya}$; $\mathrm{T}=$ Tidak 


\section{Pembahasan}

Berdasarkan hasil observasi peneliti dilapangan didapatkan di RS TNI AD Tk IV 02.07.04 Bandar Lampung, sudah dilakukan Identifikasi pada semua pasien sebelum diberikan pelayanan kesehatan termasuk pemberian gelang identitas untuk pasien yang memiliki potensi resiko tinggi celaka. Identifikasi Pasien RS terdiri dari identifikasi pasien rawat jalan dan pasien rawat inap. Pada pedoman identifikasi ini, identifikasi lebih ditujukan pada identifikasi pasien rawat inap. Identifikasi Pasien RS TNI AD Tk IV 02.07.04 Bandar Lampung adalah proses untuk mengidentifikasi terhadap pasien yang menjalani perawatan atau menjalani serangkaian tindakan/prosedur terapi/ diagnostik di RS TNI AD Tk IV 02.07.04 Bandar Lampung. Identifikasi pasien dilakukan agar pasien mendapatkan pelayanan dan pengobatan yang benar dan tepat sesuai kebutuhan/instruksi medis, terhindar dari kemungkinan terjadinya kesalahan dalam memberikan pelayanan dan agar pasien merasa aman dan nyaman serta dapat bekerjasama dalam menjalani perawatan atau prosedur layanan di RS TNI AD Tk IV 02.07.04 Bandar Lampung.

Penelitian Mulyana tahun 2013 mengenai analisis penyebab insiden keselamatan pasien oleh perawat di unit rawat inap rumah sakit " $X$ " Jakarta menlaporkan bahwa kejadian insiden kejadian keselamatan pasien (IKP) berhubungan erat dengan faktor individu atau karektirisktik SDM yang bekerja. ${ }^{10}$ Penelitian Sumangkut tahun 2015 tentang evaluasi penatalaksanaan sasaran keselamatan pasien di RSU GMIM Kalooran Amurang melaporkan bahwa ketepatan identifikasi pasien di RSU GMIM Kalooran menggunakan gelang identitas dalam penerapannya, peningkatan komunikasi yang efektif, menggunakan SBAR dengan menggunakan jembatan keledai. Peningkatan keamanan obat yang perlu diwaspadai memiliki daftar obat, disimpan dalam lemari terkunci, bila digunakan dilakukan double check, kepastian tepat lokasi, tepat prosedur, tepat pasien operasi di RSU GMIM, dan pengurangan risiko infeksi. ${ }^{11}$

Berdasarkan hasil wawancara dengan informan menyatakan bahwa semua tindakan yang berhubungan dengan pasien ada SOP RS TNI AD Tk IV 02.07.04 Bandar Lampung yang mengisyaratkan patient safety, sebagai contoh ketika melakukan tindakan injeksi kepada pasien maka diharuskan untuk mengenali terlebih daluhu obat yang akan diinjeksikan, mengidentifikasi dan memverifikasi pasien mulai dari nama, status dan jenis keluhanya.

SOP memungkinkan petugas kesehatan melaksanakan pelayanan sesuai dengan yang seharusnya diberikan. Seorang petugas kesehatan harus selalu berkomunikasi dengan pasien dalam melakukan proses perawatan kesehatan. Pasien memiliki peran penting dalam proses membantu petugas kesehatan dalam menentukan diagnosis dengan memberikan informasi yang jelas dan nyata, memberikan putusan tentang perawatan yang tepat, memastikan perawatan dan pengobatan telah dikelola dengan baik oleh petugas kesehatan, mengidentifikasi kejadian yang tidak diharapkan dan mengambil tidakan yang sesuai Komunikasi yang efektif adalah komunikasi yang berusaha memilih cara yang tepat agar gambaran dalam benak dan isi kesadaran dari komunikator dapat dimengerti, diterima bahkan dilakukan oleh komunikan. $^{12}$

Studi yang dilakukan Keles di RS Dr. Sam Ratulangi Tondano melaporkan bahwa pelaksanaan komunikasi pasien, komunikasi efektif, peningkatakan keamanan obat, pelaksanaan kepatian tepat-prosedur, tepat-lokasi, tepat-pasien sudah sesuai dengan standar akreditasi rumah sakit versi 2012. Sedangkan pelaksanaan pengurangan risiko infeksi dan risiko pasien jatuh belum sesuai dengan standar akreditasi rumah sakit versi $2012 .{ }^{13}$

Hasil observasi dapat dilihat bahwa lemari khusus untuk penyimpanan obat 
high alert dan elekrolit konsentrat sudah ada, tetapi label khusus obat high alert dan elektrolit konsentrat masih dalam proses pemesanan. Berdasarkan analisis kejadian berisiko dalam proses pelayanan kefarmasian, kejadian obat yang merugikan (adverse drug events), kesalahan pengobatan (medication errors) dan reaksi obat yang merugikan (adverse drug reaction) menempati kelompok urutan utama dalam keselamatan pasien yang memerlukan pendekatan sistem untuk mengelola, mengingat kompleksitas keterkaitan kejadian antara "kesalahan merupakan hal yang manusiawi" (to error is human) dan proses farmakoterapi yang sangat kompleks. Faktor lain yang memengaruhi terjadinya risiko obat tersebut adalah multifaktor dan multiprofesi yang kompleks: jenis pelayanan medik, banyaknya jenis dan jumlah obat per pasien, faktor lingkungan, beban kerja, kompetensi karyawan, kepemimpinan dan sebagainya. Pendekatan sistem bertujuan untuk meminimalkan risiko dan mempromosikan upaya keselamatan penggunaan obat termasuk alat kesehatan yang menyertai. ${ }^{14}$

Untuk memastikan sistem berjalan sesuai dengan tujuan diperlukan data yang akurat, yang dapat diperoleh melalui upaya pelaporan kejadian. Keberanian untuk melaporkan kesalahan diri sendiri tidaklah mudah apalagi jika ada keterkaitan dengan hukuman seseorang. Pendekatan budaya tidak saling menyalahkan (blame free cullture) terbukti lebih efektif untuk meningkatkan laporan dibandingkan penghargaan dan hukuman (Rewards and punishment). Untuk mengarahkan intervensi dan monitoring terhadap data yang tersedia, diperlukan metode analisis antara lain. Metode Analisa Sederhana untuk risiko ringan, root cause analysis untuk risiko sedang dan Failure Mode Error Analysis untuk risiko berat atau untuk langkah pencegahan. ${ }^{15}$

Studi yang dilakukan Bagian Farmakologi Universitas Gajah Mada (UGM) antara 2012-2014 menunjukkan bahwa medication error terjadi pada $97 \%$ pasien Intensive Care Unit (ICU) antara lain dalam bentuk dosis berlebihan atau kurang, frekuensi pemberian keliru dan cara pemberian yang tidak tepat. Lingkup perpindahan/perjalanan obat (meliputi obat, alat kesehatan, obat untuk diagnostik, gas medis, anastesi) : obat dibawa pasien di komunitas, di rumah sakit, pindah antar ruang, antar rumah sakit, rujukan, pulang, apotek, praktek dokter. Multidisiplin problem : dipetakan dalam proses penggunaan obat : pasien/care giver, dokter, apoteker, perawat, tenaga asisten apoteker, mahasiswa, teknik, administrasi, pabrik obat. ${ }^{16}$

Apoteker berada dalam posisi strategis untuk meminimalkan medication errors, baik dilihat dari keterkaitan dengan tenaga kesehatan lain maupun dalam proses pengobatan. Kontribusi yang dimungkinkan dilakukan antara lain dengan meningkatkan pelaporan, pemberian informasi obat kepada pasien dan tenaga kesehatan lain, meningkatkan keberlangsungan rejimen pengobatan pasien, peningkatan kualitas dan keselamatan pengobatan pasien di rumah. Data yang dapat dipaparkan antara lain dari menurunnya (46\%) tingkat keseriusan penyakit pasien anak, meningkatnya insiden berstatus nyaris cidera (dari 9\% menjadi $851 \%$ ) dan meningkatnya tingkat pelaporan insiden dua sampai enam kali lipat (effect of pharmacist-led pediatrics medication safety team on medicationerror reporting). ${ }^{17}$

Hasil penelitian menunjukkan bahwa sasaran IV sudah terlaksana dengan baik, dari 3 dokter dan 3 perawat yang diamati semuanya telah melakukan tepat lokasi, tepat prosedur dan tepat pasien operasi sesuai dengan standar. Salah-lokasi, salahprosedur, salah-pasien operasi, adalah kejadian yang mengkhawatirkan dan biasa terjadi di rumah sakit. Kesalahan ini adalah akibat dari komunikasi yang tidak efektif atau tidak adekuat antara anggota tim bedah, kurang/ tidak melibatkan pasien di dalam penandaan lokasi (site marking), dan 
tidak ada prosedur untuk memverifikasi lokasi operasi. Di samping itu juga asesmen pasien yang tidak adekuat, penelaahan ulang catatan medis tidak adekuat, budaya yang tidak mendukung komunikasi terbuka antar anggota tim bedah, permasalahan yang berhubungan dengan resep yang tidak terbaca (illegible handwriting) dan pemakaian singkatan adalah merupakan faktor-faktor kontribusi yang sering terjadi.

Checklist Keselamatan Pasien yang dikeluarkan oleh Organisasi Kesehatan Dunia (WHO) dan kolaborasi dengan Harvard School of Public Health USA, checklist adalah: langkah - langkah kunci dalam mengidentifikasi keamanan selama perawatan pra-operatif yang harus dicapai dalam setiap operasi tunggal tidak tergantung jenis operasi. Dan ini telah secara signifikan dapat mengurangi komplikasi dan kematian akibat operasi. Time Out Checklist menurut WHO adalah: berhentinya tim sesaat sebelum penyayatan kulit untuk menverifikasi kembali kelengkapan pemeriksaan dengan melibatkan semua tim. ${ }^{18}$ Tim ruang operasi melaksanakan Checklist WHO memiliki tanggung jawab bersama untuk memastikan bahwa lokasi yang benar telah diidentifikasi sebelum dimulainya operasi.

$$
\text { Hasil observasi pelaksanaan }
$$

pencegahan infeksi dari cuci tangan dengan handrub, dapat dilihat dari tabel di atas bahwa dokter dan perawat sudah melakukan 5 momen cuci tangan sesuai dengan pedoman 5 momen cuci tangan. Sehingga dapat dikatakan bahwa mencuci tangan sesuai dengan 6 langkah-langkah dalam 5 momen cuci tangan dengan handrub atau dengan handwash sudah efektif dilakukan baik oleh dokter dan perawat di IGD. Pokok dari eliminasi infeksi ini maupun infeksi lain adalah cuci tangan (hand hygiene) yang tepat. Pedoman hand hygiene yang berlaku secara internasional bisa diperoleh dari WHO. ${ }^{19}$ Hand washing sebaiknya dipilih produk bermutu yang mengandung chlorhexidin $2 \%$ yang efektif untuk membunuh mikroorganisme melalui kontak. Tidak disarankan untuk mengencerkan handwash yang telah disediakan dalam kandungan yang sesuai untuk tetap menjaga efektifitas dan daya kerja handwash tersebut. Beberapa petugas mengalami iritasi kulit dengan menggunakan sabun cuci tangan atau handwash. Hal ini dapat diatasi dengan pengunaan handrub yang berbasis alkohol yang lebih aman di kulit. Alcohol based handsrubs ini sangat efektif karena dapat diproduksi sendiri melalui proses aseptis di instalasi farmasi, pelaksanaannya sangat singkat hanya 20 sampai dengan 30 detik , tersedia di berbagai tempat atau portable sehingga mudah dijangkau. Sebelum menggunakan yakinkan tangan harus kering untuk mengefektifkan kerja alcohol. $^{20}$ Hasil penelitian menunjukkan bahwa perawat dan dokter yang diamati telah melakukan asesmen pasien dengan resiko jatuh sesuai dengan standar. Hasil observasi menunjukkan tersedia bed side rail tetapi tidak di semua tempat tidur pasien tersedia, pegangan besi tidak dipasang di toilet, lantai bukan antislip dan kursi roda selalu ada. Jumlah kasus jatuh menjadi bagian yang bermakna penyebab cidera pasien rawat inap.

\section{Kesimpulan}

Usaha yang dilakukan oleh staf IGD RS TNI AD Tk IV Bandar Lampung dalam membangun sistem keselamatan pasien adalah dengan melakukan proses identifikasi pasien dengan benar pada semua pasien yang masuk ke IGD, komunikasi yang melibatkan pasien sesuai SOP yang mengisyaratkan keselematan pasien, penempata obat-obat high alert yang tidak disatukan, setting ruang tindakan IGD yang sesuai dengan keselamatan pasien, proses manajemen risiko infeksi dengan selalu terdapatnya handrub dan hadwash pada westafel, pengaman karet diturunan jalan. Akan tetapi ada beberapa hal yang perlu diperhatikan pengawasannya dalam mencegah cidera pasien risiko jatuh dikarenakan belum adanya lantai anti slip 
di IGD dan belum terpasangnya hand rail di kamar mandi IGD dan bed side rail belum tersedia di semua tempat tidur IGD.

Hal ini juga didukung dengan kesadaran semua staf akan nilai keselamatan pasien dan menerapan budaya keselamatan pasien dalam pemberian pelayanan kesehatan yang ada di IGD sudah dilakukan sesuai dengan protap SOP yang sudah berlaku di Rumah Sakit, ikut bertanggungjawab dalam sistem manajemen keselamatan pasien, kemauan dalam mencanangkan selalu gerakan patient safety, laporan triwulan yang selalu dilaporkan kepada Tim KKP-RS sesuai peraturan, dan ikut serta dalam mencari jalan keluar dari insiden yg terjadi agar tidak terulang kembali.

\section{Daftar Pustaka}

1. Presiden Republik Indonesia. UU No. $44 \mathrm{Th}$ 2009 tentang Rumah Sakit. Jakarta; 2009.

2. Kementerian Kesehatan RI. Pedoman Nasional Keselamatan Pasien Rumah Sakit Kementerian Kesehatan Republik Indonesia. Jakarta; 2015.

3. Komite Keselamatan Pasien Rumah Sakit. Pedoman Pelaporan Insiden Keselamatan Pasien (IKP). Jakarta; 2008.

4. Utarini A. Kompetensi Manajer Rumah Sakit Dalam Pengembangan Patient Centered Care. Disampaikan Dalam Seminar Ilmiah 20 tahun MMR UGM Dan Forum Mutu IHQN VIII. Yogyakarta 10-13 Oktober 2012. 2012;

5. Kementerian Kesehatan RI. Peraturan Menteri Kesehatan Republik Indonesia No. 340 Tahun 2010 tentang Klasifikasi Rumah Sakit. Jakarta; 2010.

6. Sakit KAR. Standar Akreditasi Rumah Sakit Edisi 1. Jakarta; 2017.

7. Rumah Sakit TNI AD. Profil dan Sejarah Rumah Sakit TNI AD Tk IV 02.07.04. Bandar Lampung [Internet]. 2009 [cited 2019 May 20]. Available from: http://rsdktdenkesyahlampung.com/sejarahdkt-denkesyah

8. Dinas Kesehatan Kota Bandar Lampung. Profil Kesehatan Kota Bandar Lampung Tahun 2014 [Internet]. Bandar Lampung; 2015. Available from: http://www.depkes. go.id/development/site/depkes/resources/down load/profil/PROFIL_KAB_KOTA_2014/1871 _Lampung_Kota_Bandar_Lampung_2014.pdf
9. Kementerian Kesehatan RI. Peraturan Menteri Kesehatan Republik Indonesia No. 11 Tahun 2017 tentang Keselamatan Pasien di Rumah Sakit. Jakarta; 2017.

10. Mulyana DS. Analisis penyebab insiden keselamatan pasien oleh perawat di unit rawat inap rumah sakit X Jakarta. Univ Indones. 2013;

11. Sumangkut NSI, Kristanto E, Pongoh J. Evaluasi Penatalaksanaan Sasaran Keselamatan Pasien Di Rumaha Sakit Umum GMIM Kalooran Amurang. Community Health (Bristol). 2017;2(2).

12. Marhaen F. Ilmu Komunikasi Teori dan Praktek. I. Jakarta: Graha Ilmu; 2010.

13. Keles AW. Analisis Pelaksanaan Standar Sasaran Keselamatan Pasien di Unit Gawat Darurat RSUD Dr. Sam Ratulangi Tondano Sesuai dengan Akreditasi Rumah Sakit Versi 2012. JIKMU. 2015;5(3).

14. Lancet T. Medical Errors in the USA: Human or Systems [Internet]. 2010 [cited 2017 May 28]. Available from: https://www.thelancet.com/journals/lancet/arti cle/PIIS0140-6736(11)60520-5/fulltext

15. National Patient Safety Agency. Seven Step to Patient Safety's An Overview Guide from NHS Staff [Internet]. 2013 [cited 2017 Sep 10]. Available from: https://improvement.nhs.uk/resources/learning -from-patient-safety-incidents/

16. Hartati H, Lolok NH, Fudholi A, Satibi S. Analisis Kejadian Medication Error pada Pasien ICU. J Manaj Dan Pelayanan Farm (Journal Manag Pharm Pract. 2014;4(2):12532.

17. Simamora S. Peran Tenaga Teknis Kefarmasian Dalam Menurunkan Angka Kejadian Medication Error. J Manaj Pelayanan Kesehat. 2011;14(04).

18. World Health Organization. Patient Safety Solutions Preamble - May 2007. Switzerland; 2007.

19. World Health Organitation. Infection Control Strategies for Specifi c Procedures in HealthCare Facilities. 2008.

20. Kementerian Kesehatan RI. Peraturan Menteri Kesehatan Nomor 27 Tahun 2017 tentang Pedoman Pencegahan Dan Pengendalian Infeksi Di Fasilitas Pelayanan Kesehatan. Jakarta; 2011. 